\title{
The ebbs and flows of policy enactments on school-related gender-based violence: Insights from Ethiopia, Zambia, Côte d'Ivoire and Togo
}

Jenny Parkes, Freya Johnson Ross, Jo Heslop

Pre-publication version: Accepted November 2019 for publication in International Journal of Educational Development 72 (2020) 102133.

\begin{abstract}
While school-related gender-based violence (SRGBV) is increasingly on the agenda of international development agencies and national governments, there is little evidence on the policy processes that can more effectively address violence. Drawing on data from studies conducted during an innovative three year action research project with UNICEF and governments in Ethiopia, Togo, Côte d'Ivoire and Zambia, this paper explores the struggles of actors and organisations engaged in developing and implementing policies linked to SRGBV at national, mid and local levels. We examine interlinked political, conceptual and resource challenges that frequently hinder the multi-dimensional work needed to respond to and prevent the many forms of everyday violence in girls' and boys' lives. Finally, we explore the potential for strengthening government structures, and networks across sectors and state and non-state organisations, that are able to support the creative work of school communities to recontextualise policies, in order to generate more effective multi-dimensional policy enactments.
\end{abstract}

\section{Introduction}

Globally, in the course of the $21^{\text {st }}$ century there has been a rapid growth in concern about the commonplace nature of gender violence in and around schools. Evidence trickled in from the 1990s, focusing at that time mainly on sexual abuse of girls (Leach et al. 2003). Since then definitions of gender violence in schools have expanded to include corporal punishment and bullying or peer violence, as well as sexual violence and harassment, in recognition of the implicit as well as explicit ways in which gender influences multiple everyday practices of violence in girls' and boys' lives (Leach and Mitchell 2006). Recent writing has emphasised the multi-dimensionality of violence, with acts of physical, sexual and emotional force embedded within everyday interactions, and rooted in the structural violence of inequitable socio-economic and political structures and institutions (Parkes et al. 2013). Inequalities relating to gender, generation, socio-economic conditions, race and sexuality intersect in underpinning violence, as found in studies in which extreme poverty was associated with increased risk of harsh forms of corporal punishment for boys in Ethiopia (Pankhurst et al 2016), and sexual coercion by teachers or older men in exchange for food, grades or school fees among Zambian girls (WLSA 2012). The term school-related gender-based violence (SRGBV) is now widely used to describe such violence, defined as "acts or threats of sexual, physical, or psychological violence occurring in and around schools, perpetrated as a result of gender norms and stereotypes and enforced by unequal power dynamics" (UNGEI 2018) _with international organisations and NGOs spearheading advocacy, programming and research (UNESCO 2014, RTI International 2016, UNESCO 2016, UNGEI 2018). In 2015, all 58 UNESCO member states signed up to the first UN resolution on SRGBV 'Learning without fear', committing governments to promote safe, non-violent, inclusive learning environments for boys and girls. Addressing violence against young people is a priority for three of the sustainable development goals (SDG 4 education, SDG5 gender, SDG 16 peace-building).

Taking action to address SRGBV is increasingly on global and national agendas, yet there is little evidence that this has reduced violence (Leach, Salvi and Dunne 2014). A recent analysis of data 
from Violence Against Children (VAC) Surveys across four countries (Cambodia, Kenya,

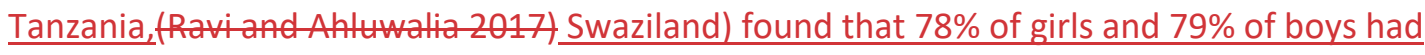
experienced some form of violence before the age of 18 years, with $20.3 \%$ of girls and $11 \%$ of boys having experienced sexual violence, including unwanted sexual touching, pressured and physical forced sex (Ravi and Ahluwalia 2017). Schools may be sites where multi-dimensional violence is performed and reinforced (Dunne 2007, Vanner 2018); and, as underlined by recent disturbing reports of sexual abuse and corruption within development agencies (House of Commons International Development Committee 2018), non-state institutions may also be implicated in reinforcing gendered relations of inequality or violence. Insights are needed into how global commitments to addressing SRGBV translate into national policies and plans; into how policies are then put to work through state and non-state structures and relationships; and into policy enactments among school communities. This paper sets out to shed light on these issues by discussing evidence from studies undertaken within an action research project on SRGBV carried out in collaboration with UNICEF and governments in Ethiopia, Togo, Côte d'Ivoire and Zambia. Drawing insights from scholarship on SRGBV interventions, gender mainstreaming, and education policy processes, we consider the ebbs and flows of policy activity at national, mid and local levels, by state and non-state actors, and conclude with implications for strengthening policy enactments.

\section{Intervening on gender and violence in schools in the global South}

Although there is a growing body of research documenting SRGBV and evaluating NGO programmes, there are few studies of policy processes on SRGBV that could generate insights into the flows between global frameworks, national policies and local enactments (Parkes et al. 2016). There is, however, some research, mainly from Africa, that sheds light on SRGBV interventions at school level, and a few studies analysing failures to implement laws and hold teachers accountable for violence. Although not focused on violence in schools, there are also valuable insights from research that explores how gender policies are understood and implemented within education sectors, and builds on a broader literature on policy flows and enactments, and on feminist scholarship on gender mainstreaming. This section discusses these strands of research, that we then use to frame our analysis.

A number of studies on school-based interventions on SRGBV in Africa demonstrate that more promising programmes engage with multi-dimensional framings, attending to the values, beliefs and norms underpinning acts of violence, as well as to the institutional cultures of schools. School institutions and systems can be challenging sites for such work, with hierarchical relationships, didactic pedagogies, curricular pressures and resource constraints mitigating against change. A recent studyin Kenya, for example, found that gender violence in schools in Kenya was exacerbated by high-stakes examination systems, which resulted in - In this context corporal punishment and peer violence being were-used to pressurise school students $s_{L}$ and extra-curricular activities and nonexamined subjects where violence prevention work could have taken place beingwere squeezed out (Vanner 2018). Successful NGO interventions with young people have managed to create 'safe spaces' enabling reflection and open discussion on sensitive topics (Campbell and Cornish 2010, Gibbs et al. 2014). Promising interventions with teachers have combined skills training with selfreflection on personal histories and beliefs regarding, for example, sexual violence or corporal punishment (Chege 2006, Duque et al. 2007). Effective school-based interventions have paid attention to creating dialogic, participatory pedagogies, and to working across whole school communities (Devries et al. 2015, McLaughlin et al. 2015). In contrast to the more commonplace short term interventions, these layered interventions, that address the norms, practices and 
structures surrounding violence, extend over years rather than weeks or months, often led by highly trained NGO staff, in some cases providing ongoing support to pupil or teacher activists in schools (Parkes and Heslop 2013, Devries et al. 2015, McLaughlin et al. 2015). Issues about sustainability remain unresolved, as their long term effects have not yet been evaluated. However, many are led by NGOs or INGOs, often working outside the mainstream school curriculum, and with programmes ending once funding ceases. The reliance on external experts for programme delivery, and the detachment from the hierarchical institutional cultures of schools can enable the creation of more participatory, facilitative contexts for engaging on sensitive issues, but can also mean little imprint is left on the institutions of children's everyday lives. Enabling schools to become 'safe' contexts for SRGBV prevention entails important implications for pedagogies and institutional cultures, posing a challenge to education sectors.

These findings point to the importance of attending to systems and structures within the education sector. However, there are remarkably few studies attending to SRGBV policy processes beyond the locale of the intervention. Some reviews have acknowledged the expansion of national legislative and policy frameworks relating to gender-based violence and SRGBV, but criticised the lack of political will, weak cross-sectoral support, and tendency to create national policies without action plans or budgetary allocation (Leach et al. 2014, Ellsberg et al. 2015). A small number of South African studies from a legal perspective have traced weaknesses in translating laws and policies linked to violence against children from national to local levels, with competing policies and directives hindering attempts at inter-sectoral approaches to violence prevention and response (Matzopoulos and Myers 2014); and poor coordination, legal inconsistencies, and lack of training or distribution of policy guidelines, leading to failures to hold teachers accountable for sexual violence (Centre for Applied Legal Studies 2014).

Another group of studies, though not focused on SRGBV, have analysed how gender policies are understood and enacted at different levels within education. Informing this work are two fields of scholarship, relating to education policy enactment and gender mainstreaming, which we briefly discuss here, as they have helped to frame the analysis for this paper. Scholars analysing flows of education policy, critiquing assumptions about linear, rational transmission, have drawn attention to the uneven and complex ways in which global or national policy formations are recontextualised over time, space and different levels (Bartlett and Vavrus 2014). The term policy enactment has been coined to denote the messy, creative processes of interpretation and recontextualization of education policies by multiple actors (Ball et al. 2012). Policy reforms are influenced by struggles among policy actors, working within strategic action fields in which they are embedded within networks, institutions and cognitive frames (Hartong and Nikolai 2017). Peck and Theodore (2010) have stressed the intrinsic politics in these processes influenced by enduring power relations and shifting ideological alignments (Peck and Theodore 2010). The politics of policy enactments has been a central concern of scholarship on why gender mainstreaming within government machineries has been so difficult to achieve (Standing 2007 ). Incorporating gender concerns within state bureaucracies can work against substantive change, with gender framed in instrumental terms and reduced to a de-politicised technical exercise, lacking insight into the complexity of gender constraints, nor how they intersect with other inequalities (Benería et al. 2015).

Gender mainstreaming within the education sector has been criticised for imposing a particular vision of gender equality, which may not be recognised or supported by those within organisations, and for paying insufficient attention to the deeply entrenched historical inequalities that suffuse public institutions, as much as families and communities (Unterhalter and North 2010). A study on the enactment of global goals on gender and education at national, district and local levels in South 
Africa and Kenya found disconnects in the vertical transmission of national policies, with gender, particularly at local levels, understood as a minimal notion of parity between girls and boys, and with horizontal disconnects in the tendency of district education officials and teachers to blame poor parents (Unterhalter et al. 2012). Several studies signal the significance of the middle space between national policy making and local implementation, with norms, professional cultures, institutional arrangements and gendered identities influencing the policy work of actors in regional and local government, professional associations and civil society organisations (DeJaeghere and Wiger 2013, Unterhalter and North 2018). The need to engage with perspectives and practices of local communities has been a key message of this work, with a number of studies stressing the bidirectional ways NGOs 'vernacularize' their programming, adapting them according to local framings (Abramowitz and Moran 2012, Sharma et al. 2013). A study in Liberia found that when NGOs attempted to vernacularize their gender-based violence programme, the disconnects between the concerns of the NGO and those of local community members exacerbated stereotypical judgements by NGO staff of 'culture' as an impediment (Abramowitz and Moran 2012). This demonstrates both the importance of dialogue, and the frictions and defensive positions that may arise.

Building on this literature, our analysis explores the ebbs and flows of SRGBV policy enactments in four countries, drawing on the insights of national, intermediate and local level policy actors, who are dynamically embedded within institutions, networks and cognitive frames. We consider the extent to which policy processes engage with multi-dimensional framings, creating the 'safe' spaces for dialogue and critical reflection that the research has signalled to be key to effective interventions on SRGBV. We pay attention to the gender politics, to the re-contextualisation of policies by actors at different levels, and consider the implications for transformative work to prevent SRGBV.

\section{Methods}

The data informing this paper stem from a three year (2014-17) initiative led by UNICEF, End Gender Violence in Schools (EGVS), with the overall aim to strengthen the production and use of evidence in SRGBV policy and practice. EGVS was designed as an action research project, carried out in collaboration with the governments of Ethiopia, Côte d'Ivoire, Togo and Zambia, UCL Institute of Education and UNICEF, funded by GPE and with support of UNGEI. The overarching action research methodology entailed engaging stakeholders systematically reflecting upon and evaluating their work in the light of research evidence, with the aim of improving both practice and the knowledge base (McNiff and Whitehead 2011). The project involved policy actors, UNICEF and researchers working together to review evidence globally and in each country, and to use this to strengthen evidence-based policy enactments.

Several research studies were conducted within the project, with the data for this paper drawn from scoping studies conducted in each country in 2016 to gather evidence on research, policy and practice on SRGBV, and from a further study of local policy enactment in Ethiopia in 2017. Data collection for the scoping studies took place through interactive workshops with policy actors in each country, semi-structured stakeholder interviews (23 in Ethiopia, 26 in Zambia, 22 in Côte d'Ivoire and 24 in Togo), and documentary analysis of policies, research and programmes. Local researchers assisted with data collection, reviewed findings and supported dissemination. Interview participants were selected to represent a broad range of sectors and non-governmental organisations working on SRGBV at national or intermediary level. Preliminary findings were shared in further workshops and through written feedback on drafts, to triangulate and check the accuracy of our interpretations. With a lack of robust existing data and patchy documentation available in 
each country, this iterative approach strengthened the ecological validity and trustworthiness of our findings.

Discussions about the scoping study findings generated country level action plans, including further research. Of particular interest for this paper is the follow up study prioritised by the Ministry of Education in Ethiopia, to investigate further scoping study findings on the uneven implementation of the SRGBV Code of Conduct, which had been piloted across the country from 2014. In collaboration with a local researcher, data was collected in six schools, three in Addis Ababa, and three in a rural area, Amhara. In-depth interviews and focus group discussions were conducted with 108 purposively sampled school students, and 34 adults, including school personnel, community and local government stakeholders, and regional and national governmental and non-governmental stakeholders.

Transcribed data for each study were coded using NVivo, with codes generated and revised based on the research questions, theoretical framing and initial examination of the data, and coding exercises used to ensure consistency among the research team. All the research conducted for the project was awarded ethical clearance by UCL Institute of Education Ethics Committee. Findings for scoping and follow up studies were validated through a series of meetings and workshops, along with discussions about the implications for policy and practice.

\section{SRGBV in policy making}

While varying social, economic and political legacies shape the policy arenas of the four countries, their evolving legislative and policy frameworks linked to SRGBV are aligned in similar ways with global and regional agendas of human rights and economic development. Policy actors interviewed for the scoping studies highlighted increasing attention to SRGBV in their work in recent years. All four countries have ratified international and regional human rights treaties, including the Convention on the Rights of the Child (CRC), the Convention on the Elimination of All Forms of Discrimination Against Women (CEDAW), and the African Charter on the Rights and Welfare of the Child (ACRWC). Their Constitutions commit the state to advance and protect children's and women's rights. Since the 1990s, they have legislated against child abuse, with penalties specified in criminal codes, and they have laws banning forced and child marriage, harmful cultural practices, forms of domestic violence, child trafficking and hazardous labour. Corporal punishment is prohibited (though in Côte d'Ivoire the Ministerial Order of 2009 has not yet been confirmed through legislation), and sexual violence by teachers banned.

Within their education sectors, in line with the MDGs and EFA goals and national goals to promote socio-economic development and poverty reduction, the emphasis is on increasing access, efficiency, equity and quality. While there has been progress towards gender parity of access in primary education, only two thirds of children are enrolled at lower secondary level in Zambia, and fewer than half in Ethiopia, Togo and Côte d'Ivoire, with girls markedly less likely to be enrolled than boys in all four countries (UNESCO 2019). Attention to gender within policies and plans in the four countries has focused mainly on addressing the continuing disparities in access and progression through school, with gender equality associated mainly with counting girls into school. Violence is mentioned only sporadically in Education Sector Plans, mainly as a barrier to access. Zambia's Education Sector $3^{\text {rd }}$ National Implementation Framework 2011-2016, for example, has a brief reference: 
"Another factor impeding gender equality in education, which does not receive appropriate attention, is the lack of safety of learners in institutions of learning, leading to sexual and other forms of abuse of children; particularly females."

The plan proposes to develop child protection policies in schools. Ethiopia's Education Sector Development Programme (ESDP V 2015) and Gender Strategy for the Education and Training Sector (2015) refer to plans to address barriers to girls' participation, including accessible, safe and healthy school environments, and implementation of the SRGBV code of conduct. Côte d'Ivoire's Education Sector Plan (2016-2025) aims to improve retention through infrastructural interventions to provide safer and healthier schooling, and mentions strengthening child protection within and on the journey to school. Togo's Education Sector Plan (2014-2025) mentions training in non-violent pedagogies, though without providing a rationale or explanation about how violence is being defined. None of the plans include SRGBV indicators or budgetary commitments in their monitoring frameworks.

While some dimensions of SRGBV are trickling into education policies and plans, the framing of SRGBV in the plans is narrow, with violence viewed mainly as child abuse, with an implicit - and in the case of Zambia explicit - concern with females as victims. Missing from the plans (with the possible though unclear exception of Togo) are preventive initiatives to tackle the gender dynamics and power relations within school communities that produce and sustain violence.

In contrast to the policy texts, many of the policy makers we interviewed were deeply concerned about the multiple layers of SRGBV but struggled to mobilise commitment to this work within and between government departments. Resource constraints necessitated close ties between Education Ministries and multi- and bi-lateral development partners, which constituted Local Education Groups steering flows of resources and policy in the sector, including bringing SRGBV onto the national agendas. Views were mixed about the influence of donors:

"As you know Zambia is one of the developing countries so at times it's a bit difficult to access these funds, but thank God we have cooperating partners who have been putting in resources to ensure that certain things are put in place, like the Anti GBV Act was developed through the GRZ UN Joint Programme ${ }^{1}$, but on the government side we don't really have enough resources to put, but most of the funds are coming from the cooperating funds" (National Government Official, Zambia)

"For most capacity building programs for teaching in our state, the funds come from our partners and it is they who define the strategy, and in that way our education system can lose its identity." (NGO worker, Togo).

"SRGBV is still not explicitly included in the ESDP, there is still weak understanding about the issue of SRGBV among many of the stakeholders, and SRGBV as a burning agenda is only reflected by a few stakeholders like UNICEF and some others [...] working on SRGBV as an agenda of development partners." (National Government official, Ethiopia)

While some interviewees in all countries, like the official from Zambia, valued the relationship with donors as supportive and collaborative, others were concerned that the dependence on foreign aid shifted control over the direction of policy away from governments, or that framing SRGBV as a

\footnotetext{
${ }^{1}$ The Government of the Republic of Zambia - United Nations Joint Programme on Gender Based Violence brings together 7 UN organisations, donors Ireland and Sweden, to work with government in coordinating policy across several sectors.
} 
foreign imposition could be deployed by less committed colleagues as a strategy to argue against prioritising such work in education planning.

Among those we interviewed across the four countries, many national government officials and others steering policy at national level were highly committed to expanding preventive as well as responsive work on SRGBV, but faced competing pressures on what is included and excluded from policies and plans, with such work seen by colleagues as marginal and externally imposed.

Nonetheless, despite these challenges in policy making, many interviewees, in non-governmental as well as government positions, felt that the emerging legislative and policy frameworks provided a solid basis for addressing SRGBV. The concern that was reiterated again and again related to policy implementation - that in schools and communities people lacked awareness of the existence of the laws and policies. To investigate this further, we turn now to the structures developed to support policy enactment.

\section{Enacting SRGBV policies}

The multi-dimensionality of SRGBV entails work in and across several sectors, with a complex set of vertical and horizontal relationships. In all four countries lead responsibility for SRGBV work rested with Ministries for Education, though other ministries also played a role. The mode of conveying national policies was through a transmission model, cascading information about laws and policies through training and awareness raising activities from national to intermediate to local levels. The vertical structures to support this varied between countries. In Ethiopia, state structures are clearly defined, in line with decentralisation policies and a gender equality machinery established through the National Women Policy 1993, and Gender Mainstreaming Guidelines 2011. The Ministry of Education infrastructure includes gender units and focal points at federal, regional and district levels, including gender focal persons and gender clubs in schools. Parallel structures in the Ministry of Women, Youth and Children's Affairs support the education sector staff.

In Zambia too, responsibility for enacting policy on SRGBV is located largely with gender focal staff, though the governmental structures are less established than in Ethiopia. Within the Ministry of Education, one national level official acts as gender focal point alongside her other duties. The Ministry of Gender also supports work on gender-based violence, but one official explained that their recent detachment from Youth and Sport had left them without resources and 'structures on the ground'. In Côte d'Ivoire at national level the Ministry of National Education, Technical Education and Vocational Training, and Ministry of Women, Child Protection and Solidarity are engaged with work on SRGBV - although it is classified in relation to child protection or gender. There is also a National Committee to Combat Violence Against Women and Children. At regional level platforms are spread across the country and work on a range of areas, including gender-based violence. In Togo the Ministry of Primary and Secondary Teaching and Professional Training has responsibility for work on SRGBV, and there is a focal person at ministry level with responsibility for several areas including gender, violence and disability. There are protection committees at regional education directorates and village development committees at local levels. Acknowledging the need to improve the Ministry's coordination of work on SRGBV in Togo, a sectoral thematic group on violence was set up in 2015, bringing together state and non-governmental policy actors. Building on the success of the group, in 2017 its remit expanded to include representatives from other ministries and sectors beyond education. At the same time work was undertaken to formalise the structure, aims and activities of the group, strengthening its focus and resourcing. This horizontal shift reflected the recognition in Togo of the value of building networks across institutions in SRGBV 
policy enactment, at the same time as strengthening the vertical structures within the education sector.

The coordinating structures for SRGBV work, therefore, varied somewhat in how well established they were, in their vertical structures for gender work, and in their horizontal relationships between sectors and state and non-state institutions. However, across the four countries, governmental and NGO interviewees shared similar concerns about the challenges with policy enactment, revolving around lack of resources and resistance to gender equality work.

State actors at all levels struggled with competing demands on funding, and difficult decisions on how to channel scarce resources. In Togo, for example, interviewees spoke of how low teaching salaries, and oversized, multi-age and under-resourced classes hindered efforts with teachers to adopt non-violent pedagogies. Inadequate budgets for SRGBV work was a major concern at national, intermediate and local levels in Côte d'Ivoire as one interviewee recounted:

It's the budgeting and the funding of the activities. It's to show a commitment, not only a political commitment but something concrete, to give budgets to the ministries in charge of the issue at hand. The true issue relating to SRGBV is to know how to fund actions. Social centres are there, people are motivated, people are working, but they do not have the budgets to work. I believe this question is crucial. (NGO worker, Côte d'Ivoire)

With severely constrained state resources, NGO programmes funded by international donors constituted a large amount of the activity to address SRGBV at local levels, particularly in Côte d'Ivoire, Togo and Zambia, though less so in Ethiopia with the regulatory restrictions on human rights NGOs following the 2009 Charities and Societies Proclamation² (Dupuy et al. 2015). Interviewees from NGOs described a broad array of initiatives, including clubs for young people, teacher training initiatives on comprehensive sexuality education, life skills and counselling, training in legal skills or community engagement, helplines and support services for victims. In Zambia, for example, FAWEZA has been influential in developing responsive and preventative programmes, such as Safe Houses for girls at risk of school drop out; Safe Spaces programmes, in which girls map out danger zones in their communities, using these to develop action and advocacy plans; and Boys Forums to engage boys in discussions on issues like hygiene, relationships and sexuality. Such NGO programmes present opportunities for creative, participatory work, and spaces for open, critical reflection and negotiation. A district official in Zambia commented that NGO led gender clubs in his district had improved girls' knowledge about sex and relationships, compensating for weaknesses in the school science curriculum, though he lamented the limited reach of these interventions, including the exclusion of boys. Many NGOs struggled to gain sustainable funding, and were constrained in their work by what donors were willing to fund. Interviewees were concerned that donor priorities led to duplication of efforts in some areas, while neglecting hard to reach locations. Though the intention may be to scale up from these small scale programmes, few organisations conducted systematic evaluations of their work, that could feed in to government policy decisions.

Problems with resourcing and co-ordination also led at times to contention between levels in the struggle to implement and roll out plans on gender-based violence. For example, in Côte d'Ivoire the functioning of the co-ordinating platforms was questioned by some state and non-state actors, with one NGO interviewee explaining:

\footnotetext{
${ }^{2}$ At the time of writing, following change of government leadership, the Charities and Societies Proclamation is under review.
} 
The problem is that the platforms don't function. And what stops the platforms from functioning is primarily that they need to bring together actors working on a specific theme. In the case of GBV, they have to meet on the issues of GBV. Today, how many NGOs have funding to participate in the fight? That's the question we are asking. Now, when people meet up through the platforms, they expect to be reimbursed for their transportation or food expenses. Yet, the secretary, the technical secretariat provided by the Ministry of Family, don't have the funds to cover transportation or food expenses. So people come once or twice, then they wonder about the future and question their participation, then stop coming. That's the fight we are tackling. (NGO worker, Côte d'Ivoire)

Lack of resources was compounded by resistance to gender equality work. Gender specialists at all levels of government spoke of problems of low status and resistance to their work from colleagues whose support for gender equality may be tokenistic, or who may actively undermine their initiatives. For example, in Ethiopia, where some control is decentralised to regions, varying commitment of provincial leaders generated uneven resourcing, with 5 gender specialists in the Addis office, but only one staff member in Ethiopia-Somali and Amhara regions. At local levels, gender was often 'added on' to the already busy workload of civil servants, who may have had little training on gender or SRGBV.

Among some interviewees, there was a tendency to blame 'culture' within communities for the difficulties with enacting policy, possibly echoing the observation of Abramowitz and Moran (2012) that stereotypical attitudes about culture could arise from and deflect attention away from implementation failures:

Since most of SRGBV cases are considered as part of the culture, in most cases parents, community, school staff, and even victims themselves are not cooperative to take the case to legal procedure and hesitant to provide evidence to substantiate the cases. (Government official, Ethiopia)

Other interviewees attributed the difficulties with implementing policies to a gender regime across society that subjugates women and girls:

It is not the limitation of the policies or the laws but of the inadequate awareness of the society in general towards SRGBV; lack of cooperation among the community and the law enforcement bodies to act against perpetrators and fear and being silent to report GBV. The law enforcement bodies have problems; they are dominated by the mentality of male superiority. As a result it is not uncommon to give less attention to concerns of women and reports of GBV. Even in some rural areas local administrators abduct young school girls for marriage. [....]The presence of teachers' network around schools is also the other area that needs attention. Teachers hide violence of colleagues in coordination. Reports of violence against teachers don't move further as a result. (NGO worker, Ethiopia)

Collusion of institutions at local levels - including police and judiciary, local political leaders, and teachers - was viewed as undermining efforts to implement SRGBV policies. The effectiveness of the structures put in place to enact SRGBV policies were, in this account, hindered by lack of knowledge or 'awareness', and attitudes about gender and women's place in society, generating subterfuge and widespread failure among local policy actors to hold perpetrators accountable. Resistance to gender equality took different forms - sometimes reflected in lack of interest or prioritising such work, at other times in actively undermining perceived threats to the gender regime, for example in risking exposing a local leader or official for sexual exploitation of a school girl. Threats to the status quo, fear of repercussions and lack of awareness of what constitutes violence were all perceived to 
hinder effective policy implementation. While many stakeholders stressed the need to build awareness among local communities, of laws and policies, as well as of what constitutes SRGBV, the transmission of information in itself does little to address these structural conditions, resource flows, and gender regimes that militate against effective policy enactments. Nor does it recognise the contestations surrounding SRGBV already operating within local communities.

\section{Engaging with SRGBV policy in schools}

We turn now to our study on Ethiopia's SRGBV Code of Conduct, because it awards a rare opportunity to consider the enactment of a national SRGBV policy at the level of the school. Since its introduction in 2014, this has been the Ministry of Education's key SRGBV policy initiative, and with UNICEF's support the Code has been adapted and translated at regional level, and rolled out in schools across the country. The Code is largely regulatory, aiming to improve accountability through setting out sanctions for SRGBV committed by staff and students, with SRGBV defined quite narrowly to include sexual harassment and abuse, but not including corporal punishment, or bullying unless explicitly gendered. Sanctions are adjudicated through SRGBV Committees comprised of 7 members, including staff, 2 students, one from the gender club, and Parent Teacher and Student Association representatives, and chaired by the gender focal teacher. The approach exemplifies the government's approach of distributed leadership, a model that purports to increase democratic participation, though some writers have argued that its primary goal is social control, through engaging children and teachers as agents in surveillance that reinforce school hierarchies (Mitchell 2017). Following scoping study findings concerning patchy implementation, the Ministry prioritised a further study to look in depth at how the Code was understood and used by school communities, and it is on this study that this section reports.

To an extent, the findings indicate that the vertical structures to mainstream gender within the education system were enabling. Following training cascaded through gender units at federal, regional and local levels, each of the 6 study schools had set up SRGBV Committees, and there was some awareness of the Code among teachers and students. However, the way that the Code was operating in practice in the schools differed from the guidance set out in the Code booklet. In all the schools, very few cases were reported through procedures set out in the Code, nor was the Code being used to proscribe sanctions. Though taboos, fear and shame may well hinder disclosures, students were quite outspoken with researchers about their experiences of violence, and yet they were reluctant to follow the reporting protocol, as in these examples about the repercussions of disclosing sexual abuse or corporal punishment:

From the side of the students they may stigmatise the victim of violence. They do not want to be friends with her anymore and as a result she may commit suicide or get in to different unnecessary actions. (Girls focus group discussion)

He [the teacher] punished us with a rubber stick - there were students where their backs were injured because of the punishment. When the school administration also came to know the case they put the blame totally on us. (Boys focus group discussion)

For these girls, reporting to the Committee was deterred by the fear that confidentiality would not be maintained, with rumours circulating and generating stigma and exclusion rather than support, a concern that was reinforced by the weak provision of services and civil society organisations in these neighbourhoods. For the boys, knowledge that their concerns about corporal punishment would be ignored or met with further punishment, deterred reporting. Students' refusal to report can thus be 
seen as resistance to the Code's weaknesses - that its sanctions do not extend to teachers committing corporal punishment, that it neglects to support survivors, nor to provide a protective environment.

Yet, though the Code can be criticised both for emphasising regulation rather than prevention, and for failing to achieve its regulatory goals, paradoxically it did generate preventive work in the schools. With few cases to judge, the SRGBV Committees, together with the gender clubs, turned their attention to other activities. Girls spoke, for example, about creating a gender library with "books that talk about issues related to violence", a uniform exchange scheme for students unable to pay for school uniforms, using drama and poetry to create community awareness, and outreach activities to confront and prevent cases of child marriage. While constrained resources and unsupportive gender regimes hindered such work in some of the schools, in others the commitment of gender focal teachers, supported by school managers and district gender focal staff, generated vibrant activity with students to prevent and respond to SRGBV. In these schools, students and staff recontextualised the policy, broadening its framing to address local concerns and the causes as well as the consequences of violence. Within some schools, the gender mainstreaming structures within the education sector helped to create spaces for students and teachers, albeit in a limited way, to speak up, criticise and advocate for change on gender and violence.

\section{Conclusion}

While momentum to address SRGBV is gaining ground globally, and in the four African countries considered in this paper, our analysis shows that policy enactments related to SRGBV are not on a straightforward trajectory, but that there are ebbs and flows in how SRGBV is framed; in the institutional arrangements deployed by governments to implement policies from national to local levels; and in the horizontal relationships between policy actors across sectors, state and non-state organisations, and among school communities. The action research approach designed by UNICEF's End Gender Violence in Schools initiative helped to bring new insights into this under-researched area, by engaging multiple policy actors in critical reflection and dialogue.

Global goals and international organisations have had dual effects on policy work in the four countries. On the one hand, they have influenced the development of education sector plans with narrow framings of SRGBV as a barrier to schooling, with girls as victims, and actions focused on responses following acts of abuse. On the other hand, they have helped to mobilise engagements among policy actors with more multi-dimensional framings, that address inequalities, power relations, and institutional norms and practices surrounding violence. For some, the broad framing of SRGBV can act as a catalyst bringing together multiple actors concerned with violence against girls and boys, and with addressing gender, in educational settings.

But these policy actors faced interconnected barriers and contestations relating to gender politics and resource constraints. Our findings echo previous studies on gender and education that have traced disconnects between national, mid and local policy actors; some evaporation of gender work in the flows between levels; and a tendency to view local cultures as an impediment (Abramowitz and Moran 2012, Sharma et al. 2013, Unterhalter and North 2018). But a novel finding was that a narrowly framed SRGBV policy could be recontextualised within schools, drawing on the concerns within school communities, and enacted by children and teachers in more multi-dimensional ways. This attests to the value of engaging with local perspectives, and has implications for the kind of localised data that might be needed to better inform policy making, such as how to capture creative, preventive work on SRGBV in, for example, SDG indicators and national data collection systems.

Our findings extend previous work that has stressed the need to pay attention to the underresearched 'missing middle' - between national policy makers and local implementers (Unterhalter 
and North 2018). The recontextualisation in the Ethiopian schools was facilitated by the vertical structures mainstreaming gender in the education sector. Locating responsibility for SRGBV work within the gender machinery of governments faces risks of low status, uneven political support, and concomitant under-resourcing, along with a potential narrowing of the framing of gender to a technical exercise that lacks insight into the complexity of gender constraints. But in some schools, the gender machinery also created a scaffold for the recontextualisation, with gender staff at local and mid levels providing valued support and dialogue that extended beyond the transmission of information on the policy. For some gender specialists at national, mid and local levels, concentrating attention onto SRGBV could generate support for their work from colleagues agreeing on the need to tackle child abuse, though mobilising resources for training and supporting these staff, and recognition of their value and expertise were constant struggles.

In conclusion, $Q$ Our analysis points to the importance of the role of the state in coordinating work on SRGBV - in steering the strategic approach, in creating structures within the education system to ensure support for and accountability of schools, and in building links across sectors. There are risks and trade offs in working through governmental systems, of political control, neglect or sidelining, with varying political will to address gender and violence combining with pressures on resources to generate uneven policy enactments. NGO interventions often had more scope for creativity and innovation, for creating safe spaces for dialogue and reflection that evade the constraining hierarchies within and pressures upon schools. But without government coordination, they are likely to be scattered and time limited, and unable to generate and sustain changes in the institutional cultures of schools, or to address the structural and systemic underpinnings to violence. Attention needs to be paid to how better to fuse these approaches into state infrastructures. Cross-sectoral working groups, such as Togo's recently established cross-sectoral thematic group, attempt to build vertical and horizontal networks, bridging between sectors and state and non-state partners to steer policy and practice on SRGBV.

For countries aiming to strengthen their work to address SRGBV, the analysis from this four country research partnership has several implications. Firstly, it points to the strengthening of gender machineries within government systems, to support the implementation of laws and policies that prevent SRGBV. In particular, there is a need to build effective, well resourced structures and expertise for work on gender and violence at mid levels - including provincial or district education offices, teacher training institutions, and related sectors (health, social welfare, police and judiciary) - to improve the support for, monitoring of and feeding up evidence concerning SRGBV policy enactment from schools. There is considerable scope for NGOs to work at this mid-level, helping to improve governmental systems for, for example, collecting, interpreting and using data on SRGBV prevention/response, or supporting practising teachers with curricula and pedagogies that promote equitable, inclusive, anti-violent schools. Finally, at school level, learning from young people their views on why they speak out or stay silent, on disciplinary systems, codes of conduct, and reporting and response, on school clubs and curriculum on gender and violence, has rich potential to feed into more effective policy enactments. Working across these multiple levels Such bridging is essential to navigate the complex ebbs and flows of SRGBV policy enactments in order to support and sustain girls' and boys' efforts to prevent violence and stay safe.

\section{References}

Abramowitz, S. and M. Moran (2012). International Human Rights, Gender- Based Violence, and Local Discourses of Abuse in Postconflict Liberia: A Problem of "Culture"? African Studies Review 55(2): 119-146.

Ball, S., M. Maguire and A. Braun (2012). How schools do policy: policy enactments in secondary schools Abingdon, Routledge. 
Bartlett, L. and F. Vavrus (2014). Transversing the vertical case study: A methodological approach to studies of educational policy as practice? . Anthropology and Education Quarterly 45(2): 131-147. Benería, L., G. Berik and M. Floro, Eds. (2015). Gender, Development and Globalization: Economics as if all people mattered. London, Routledge.

Campbell, C. and F. Cornish (2010). Towards a "fourth generation" of approaches to HIV/AIDS management: creating contexts for effective community mobilisation. AIDS Care-Psychological and Socio-Medical Aspects of AIDS/HIV 22: 1569-1579.

Centre for Applied Legal Studies (2014). Sexual violence by educators in South African schools: Gaps in accountability. , University of the Witwatersrand School of Law.

Chege, F. (2006). 'He put his hands between girls' thighs': using student teachers' memories to tackle gender violence. Combating gender violence in and around schools. F. Leach and C. Mitchell. London, Trentham: 189-198.

DeJaeghere, J. and N. P. Wiger (2013). Gender discourses in an NGO education project: Openings for transformation toward gender equality in Bangladesh. International Journal of Educational Development 33: 557-565.

Devries, K., L. Knight, J. Child, A. Mirembe, R. Nakuti, J. Sturgess, E. Allen, N. Kyegombe, J. Parkes, E. Walakira, D. Elbourne, C. Watts and D. Naker (2015). The Good School Toolkit for reducing physical violence from school staff to primary school students: a cluster-randomised controlled trial in Uganda. Lancet Global Health 3: 378-386.

Dunne, M. (2007). Gender, sexuality and schooling: Everyday life in junior secondary schools in Botswana and Ghana. International Journal of Educational Development 27: 499-511.

Dupuy, K., J. Ron and A. Prakash (2015). Who survived? Ethiopia's regulatory crackdown on foreignfunded NGOs. Review of International Political Economy 22(2): 419-456.

Duque, L., J. Orduz, J. Sandoval, B. Caicedo and J. Klevens (2007). Lessons learned from an early intervention violence prevention program in Medellin, Colombia. Revista Panamericana De Salud Publica-Pan American Journal of Public Health 21: 21-19.

Ellsberg, M., D. Arango, M. Morton, F. Gennari, S. Kiplesund, M. Contreras and C. Watts (2015). Prevention of violence against women and girls: what does the evidence say? . Lancet 385: 15551566.

Gibbs, A., J. Rachel, M. Nompumelelo, W. Laura and W. Samantha (2014). Jobs, food, taxis and journals: Complexities of implementing Stepping Stones and Creating Futures in urban informal settlements in South Africa. African Journal of AIDS Research 13: 161-167.

Hartong, S. and R. Nikolai (2017). Observing the 'local globalness' of policy transfer in education. Comparative Education Review 61, 3 61(3): 519-537.

House of Commons International Development Committee (2018). Sexual exploitation and abuse in the aid sector. London, UK, House of Commons.

Leach, F., M. Dunne and F. Salvi (2014). School-Related Gender-Based Violence: A global review of current issues and approaches in policy, programming and implementation responses to SchoolRelated Gender-Based Violence (SRGBV) for the Education Sector. Paris, UNESCO Education Sector. Leach, F., V. Fiscian, E. Kadzamira, E. Lemani and P. Machakanja (2003). An Investigative Study of the Abuse of Girls in African Schools. London, DfID.

Leach, F. and C. Mitchell, Eds. (2006). Combating Gender Violence In and Around Schools. Stoke on Trent, Trentham.

Matzopoulos, R. and J. Myers (2014). The Western Cape Government's New Integrated Provincial Violence Prevention Policy Framework: Successes and challenges. Aggression and Violent Behavior 19: 649-654.

McLaughlin, C., S. Swartz, M. Cobbett and S. Kiragu (2015). Inviting Backchat: How schools and communities in Ghana, Swaziland and Kenya support children to contextualise knowledge and create agency through sexuality education. International Journal of Educational Development 41: 208-216. McNiff, J. and J. Whitehead (2011). All You Need to Know About Action Research. London, Sage. 
Mitchell, R. (2017). Democracy or control? The participation of management, teachers, students and parents in school leadership in Tigray. International Journal of Educational Development 55: 49-55. Parkes, J. and J. Heslop (2013). Stop violence against girls in school: A cross-country analysis of change in Kenya, Ghana and Mozambique. London, ActionAid International.

Parkes, J., J. Heslop, F. Johnson Ross, R. Westerveld and E. Unterhalter (2016). A Rigorous Review of Global Research Evidence on Policy and Practice on School-Related Gender-Based Violence. New York, UNICEF.

Parkes, J., J. Heslop, S. Oando, S. Sabaa, F. Januario and A. Figue (2013). Conceptualizing gender and violence in research: insights from studies in schools and communities in Kenya, Ghana and Mozambique International Journal of Educational Development 33(6): 546-556.

Peck, J. and N. Theodore (2010). Mobilizing policy: Models, methods, and mutations. Geoforum 41: 169-174.

Ravi, S. and R. Ahluwalia (2017). What explains childhood violence? Micro correlates from VACS surveys. Psychology, Health \& Medicine 22(S1): 17-30.

RTI International (2016). Conceptual Framework for Measuring School-Related Gender-Based Violence (SRGBV). Washington DC, USAID.

Sharma, P., G. Verma and A. Arur (2013). Negotiating meanings of gender justice: Critical reflections on dialogs and debates in a non-governmental organization (NGO). International Journal of Educational Development 33: 576-584.

Standing, H. (2007). Gender, myth and fable: the perils of mainstreaming in sector bureaucracies. Feminisms in Development: Contradictions, Contestations and Challenges. A. Cornwall, E. Harrison and A. Whitehead. London, Zed Books: 101-111.

UNESCO (2014). School-related Gender-Based Violence in the Asia-Pacific Region. Bangkok, UNESCO. UNESCO (2016). Global guidance on addressing school-related gender-based violence. Paris, UNESCO.

UNESCO (2019). 2019 Global Education Monitoring Report. Paris, United Nations Educational, Scientific and Cultural Organization.

UNGEI (2018). A Whole School Approach to Prevent School-Related Gender-Based Violence. New York, United Nations Girls Education Initiative.

Unterhalter, E. and A. North (2010). Assessing gender mainstreaming in the education sector: depoliticised technique or a step towards women's rights and gender equality? Compare 40(4): 389404.

Unterhalter, E. and A. North (2018). Education, Poverty and Global Goals for Gender Equality: How People Make Policy Happen. London, Routledge.

Unterhalter, E., C. Yates, H. Makinda and A. North (2012). Blaming the poor: Constructions of marginality and poverty in the Kenyan education sector. Compare 42(2): 213-233.

Vanner, C. (2018). 'This is a competition': The relationship between examination pressure and gender violence in primary schools in Kenya. International Journal of Educational Development 62: $35-46$. 